\title{
Effect of Ambient Temperature on Ignition Delay, Combustion Process and Emission of Biodiesel Derived from Algae
}

\section{Amir Khalid ${ }^{1, *}$, Ridwan Saputra Nursal ${ }^{1,2}$, Deden Witarsyah Jacob ${ }^{3}$, Norrizam Jaat $^{1}$, Norshuhaila Mohamed Sunar ${ }^{1}$, Shahrin Hisham Amirnordin ${ }^{4}$}

\author{
${ }^{1}$ Automotive and Combustion Synergies Technology Group, Faculty of Engineering Technology, Universiti Tun \\ Hussein Onn Malaysia,84600, Pagoh, Johor, Malaysia. \\ ${ }^{2}$ Deparment of Marine Engineering, Politeknik Bagan Datuk, 36400, Perak, Malaysia. \\ ${ }^{3}$ Telkom University, Jalan Telekomunikasi No.1 Terusan Buah Batu Bandung Indonesia. \\ ${ }^{4}$ Combustion Research Group (CRG), Centre for Energy and Industrial Environment Studies (CEIES), Universiti Tun \\ Hussein Onn Malaysia, 86400 Batu Pahat, Johor, Malaysia.
}

Received 28 June 2018; accepted 1 August 2018, available online 5 August 2018

\begin{abstract}
Global warming and energy crises have increased the awareness about eco-friendly fuels and also accelerated the search of alternative fuels. Biodiesel is defined as methyl esters of long chain fatty acids derived from vegetable oils or animal fats or similar which conform to ASTM D6751 specifications for use in diesel engines. However, low temperature combustion mode has attracted widespread attention in particulate matter and NOx emissions reduction simultaneously. Thus, this paper evaluates the potential of using algae as the alternative fuel for diesel engines and focuses on experimental investigation for the influence of ambient temperature on ignition delay and emission with different types of biodiesel. A Rapid Compression Machine (RCM) is used for simulated the diesel combustion as similar in the real diesel engine. Besides, two types of biodiesel blends, B2 ( $2 \mathrm{vol} \%)$ such as Algae and Jatropha biodiesel were tested on RCM at injection pressure of $130 \mathrm{MPa}$ under different ambient temperatures from $750 \mathrm{~K}$ to $1100 \mathrm{~K}$. The experimental results were compared with Palm-Oil biodiesel with blending ratio of $5 \mathrm{vol} \%, 10 \mathrm{vol} \%$ and $15 \mathrm{vol} \%$. Nevertheless, the result indicated that the ignition delay is slowed when ambient temperature is increased. These phenomena can be explained by the thermal properties of fuels. Ignition delay is found to be slower if premixed combustion process is reduced and also higher ambient temperature due to the increased in fuel ignitibility. The emission of NOx increased as the ambient temperature increased to cause highly combustion temperature.
\end{abstract}

Keywords: Algae Biodiesel, Combustion Process, Rapid Compression Machine, Ambient Temperature, Emission

\section{Introduction}

Rapid depletion of fossils fuel has revived the importance of biodiesel use in diesel engine nowadays. Highly usage in fossil fuel results high harmful gases emissions and also play a significant part in the global warming. Reduction in usage of fossil fuel has been studied previous via renewable energy development such as solar, wind, hydro and biodiesel [1-4]. However, biodiesel is the fuel that made from vegetable or animal oil and it is environmental friendly. Besides, biodiesel is found as the alternative fuel which capable to reduce the emission of hydrocarbon (HC), carbon monoxide (CO), and particulate matter (PM) but effectuated the increasing on Nitrogen Oxide (NOx) emission [3-7]. The number of studies that have evaluated the potential of using biodiesel from algae and the main used of biodiesel leads to the highly reduction in $\mathrm{HC}, \mathrm{CO}$ and $\mathrm{PM}$ emissions without power loss and increasing fuel consumption [6-
8]. Microalgae is a photosynthetic organism that widely known about its high photosynthesis efficiency, short growth cycle, high biomass yield and high lipid content when compared with the terrestrial energy plants. Since most of earth surface covered by water, algae biodiesel would be great renewable energy due to it has higher chance living in water [9]. Aquatic unicellular green algae are the most common algae that used in biodiesel production. This type of algae is a photosynthetic eukaryote characterized by high growth rates and high population densities. Oil content found in green algae is the main criteria that considered for species selection to culture that will be used as natural resources for biodiesel production [10].

During the combustion process of diesel engines, the period that between the start of injection and the first sign of ignition is called as ignition delay [11]. Moreover, ignition delay also defined as the period of stagnation 
between the time when first droplet of atomized fuel hit the preheated air inside combustion chamber and the time when actual burning phase start. Besides, Ignition delay is also known as the preparatory phase when some fuel has been injected but yet to ignite. Nevertheless, ignition delay is a major factor to determine the rapid pressure rise at the initial burning stage and subsequent combustion [12-13]. Other than that, ignition delay not only directly affects to the engine performance and combustion noise, but it also plays an important role in the formation of pollutants such as nitrogen dioxide (NOx) and particulate matter (PM).

Combustion temperature gives impact to the diesel combustion. An advanced combustion mode such as low temperature combustion has attracted widespread attention in recent years for the purpose of reduction in PM and NOx emissions simultaneously [13]. Ignition delay and flame lift-off length are the important parameters which have great influences to the spray flame structure and soot formation tendency. Studies have been carried out on spray and combustion characteristics in a premixed-burn constant volume vessel using acetonebutanol-ethanol (ABE) and diesel blends. It is found that lower ambient temperature could prolong both ignition delay and lift-off length, which usually indicates inhibited soot formation. Moreover, it is reported that decrease of temperature in the chamber caused ignition delay period became longer and soot concentration decreased [14-15]. All previous studies on dual fuel combustion modes suggested a strong relation between emission formation and ambient temperature. Apart from that, emission is the main disadvantage in diesel engine since it gives harmful effect to human and environment. High level of PM and unburned hydrocarbon will be generated in the diesel engine due to low oxygen content of fossils fuel which leads to incomplete combustion [15-17].

In this paper, the characteristics of combustion properties are investigated experimentally focusing on the ignition delay and emission with variant ambient temperatures in Rapid Compression Machine (RCM) in order to understand the potential of using algae as the alternative fuel for diesel engines. The experimental result obtained was compared with the result of Palm-Oil biodiesel for the validation purpose. Meanwhile, the difference between Algae biodiesel with Jatropha biodiesel and Palm-Oil biodiesel were studied for investigation of the persistence of whole algae characteristics during the fuel injection and combustion processes.

\section{Methodology}

Two types of biodiesel blends fuel, B2 (2vol\% biodiesel blends with $98 \mathrm{vol} \%$ of diesel) were prepared with Algae biodiesel (A2) and Jatropha biodiesel (J2). However, Botryococcus braunii is a type of algae species that used in this experiment. Figure 1 displays the blending machine used which shows a block diagram of blending process and schematic view of blending process are shown in Figure.1 (a) and Figure.1 (b), respectively.

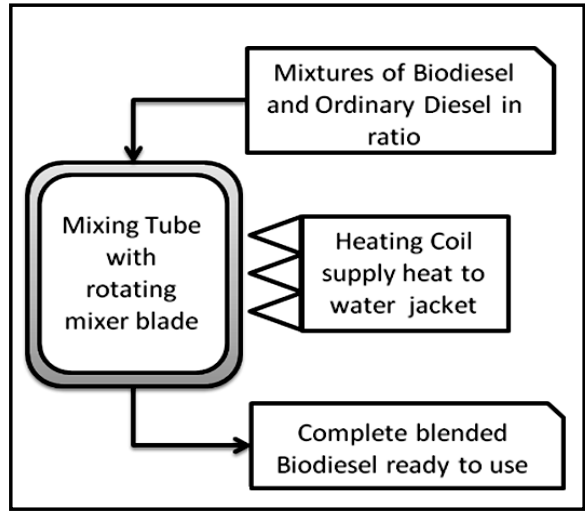

(a) Schematic of blending process

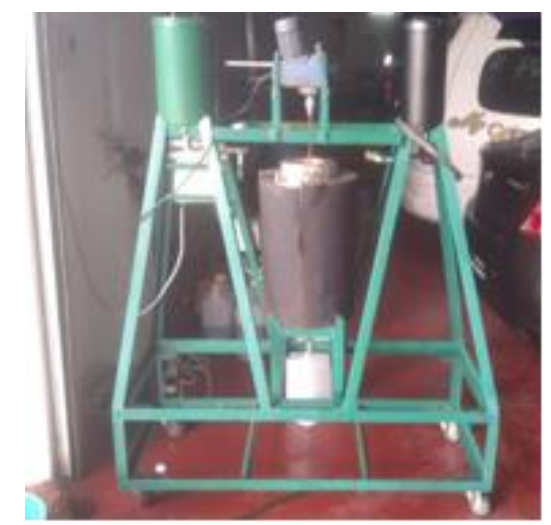

(b) Biodiesel Blending Machine

Fig. 1: Biodiesel Blending Machine

Table 1: Fuel Properties

\begin{tabular}{ccc}
\hline \multirow{2}{*}{ Fuel Type } & \multicolumn{2}{c}{ Properties } \\
\cline { 2 - 3 } & Density $\left(\mathbf{g} / \mathbf{m}^{\mathbf{3}}\right)$ & $\begin{array}{c}\text { Kinematic Viscosity } \\
(\mathbf{C p})\end{array}$ \\
\hline A0 & 0.860 & 4.4 \\
A5 & 0.831 & 3.6 \\
J0 & 0.878 & 4.3 \\
J10 & 0.838 & 3.6 \\
B5 & 0.837 & 3.0 \\
B10 & 0.838 & 2.9 \\
B15 & 0.840 & 3.0 \\
\hline
\end{tabular}

During the blending process, the purified palm oil methyl ester was then blended with STD in various concentrations for preparing biodiesels blend. During the blending process, mixture was stirred at $70 \mathrm{oC}$ for 2 hours and with the rotating blade speed fixed at 270 RPM. The fuel was tested in the RCM and the result obtained is discussed. Besides, Table 1 illustrates the fuel properties of Algae biodiesel, Palm oil biodiesel and Jatropha biodiesel which used in this experiment. A0 and $\mathrm{J} 0$ represented the crude Algae and Jatropha oil while B5, B10 and B15 are the Palm-Oil biodiesel with blending ratio of $5 \mathrm{vol} \%$ to $15 \mathrm{vol} \%$. Meanwhile, Table 2 
summarized all the experimental conditions used in this study.

Table 2: Experimental Conditions

\begin{tabular}{ccc}
\hline \multirow{3}{*}{ Fuel } & Injector type & $\begin{array}{c}6 \text { holes, } \emptyset=0.16 \\
\mathrm{~mm}\end{array}$ \\
\cline { 2 - 3 } & Fuel type & $\mathrm{A} 2$ and $\mathrm{J} 2$ \\
& $\mathrm{P}_{\mathrm{inj}}[\mathrm{MPa}]$ & 80,90 and 130 \\
& $\mathrm{q}_{\mathrm{i}}[\mathrm{ml}]$ & 0.04 \\
\hline \multirow{4}{*}{ Ambient } & $\mathrm{T}_{\mathrm{i}, \mathrm{cvc}}\left[{ }^{0} \mathrm{C}\right]$ & 70,80 \\
& $\mathrm{r}_{\mathrm{s}}[\mathrm{m} / \mathrm{s}]$ & 19 \\
& $\rho\left[\mathrm{kg} / \mathrm{m}^{3}\right]$ & 16.6 \\
& $\mathrm{O}_{2}[\mathrm{vol} \%]$ & 21 \\
\hline
\end{tabular}

Apart from that, a schematic diagram of Rapid Compression machine is shown in the Figure 2, which indicated with the single shot common rail fuel injection system. The behaviour gas pressure inside the combustion chamber was measured by a piezoelectric pressure transducer (Kistler, 601A). A free moving piston inside cylinder liner was pushed with the pressure of 19 bar, which is the constant pressure applied throughout whole experiment. The temperature of combustion chamber is heated to required conditions. All connections for the equipment are sealed tightly to avoid leaking such as piston, cylinder liner, combustion chamber, nitrogen gas, injector jigs and diaphragms. Moreover, injection pressure of $130 \mathrm{MPa}$ was supplied, while the pressure and voltage graph is automatically recorded by the oscilloscopes of PICO 3000 series. As far as emission is concerned, the emission is collected at exhaust valve after combustion is finished. The emission is then analysed by the gas analyser to obtain the percentage for each emission components such as nitrogen oxides (NOx) and particulate matter (PM) emissions.

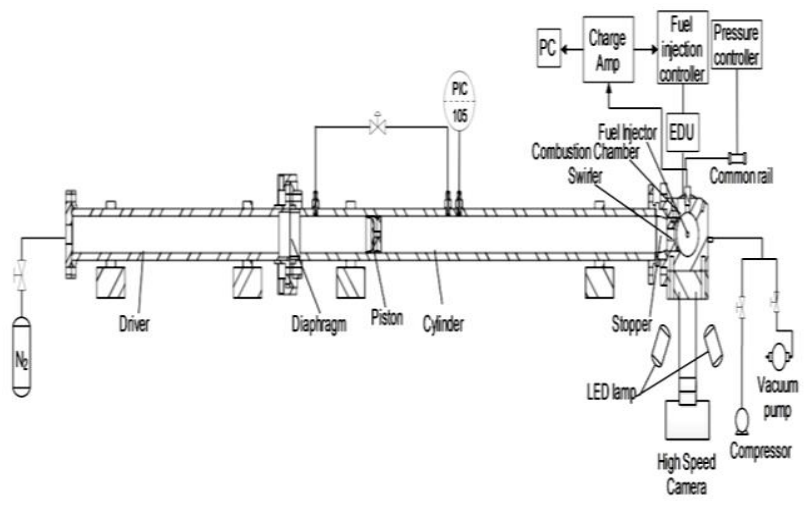

Fig. 2: Schematic Diagram of RCM

\section{Results and Discussion}

3.1 Effect of ambient temperature on injection duration and emission for different biodiesel.

The aim of this section is to investigate the effect of algae biodiesel on ignition delay and emission under variant injection pressures and ambient temperature using Rapid Compression Machine (RCM). For validation purpose, a comparison is made between five types of blend biodiesel which are Palm-Oil Biodiesel (B5, B10, B15), A2 and J2 in this experiment. Influence of blending ratio on injection duration was firstly investigated for different types of biodiesel blend. The investigated initial charging pressure were $\mathrm{Pc}=0.1 \mathrm{MPa}$, that corresponded to the ambient densities of $\rho=16.6 \mathrm{~kg} / \mathrm{m}^{3}$, while swirl velocity is kept constant at $\mathrm{r}=19 \mathrm{~m} / \mathrm{s}$. Fuel was injected by a $6-$ hole injector with hole-diameter of $0.16 \mathrm{~mm}$ and injection pressure, $\mathrm{P}_{\text {inj }}=130 \mathrm{MPa}$.

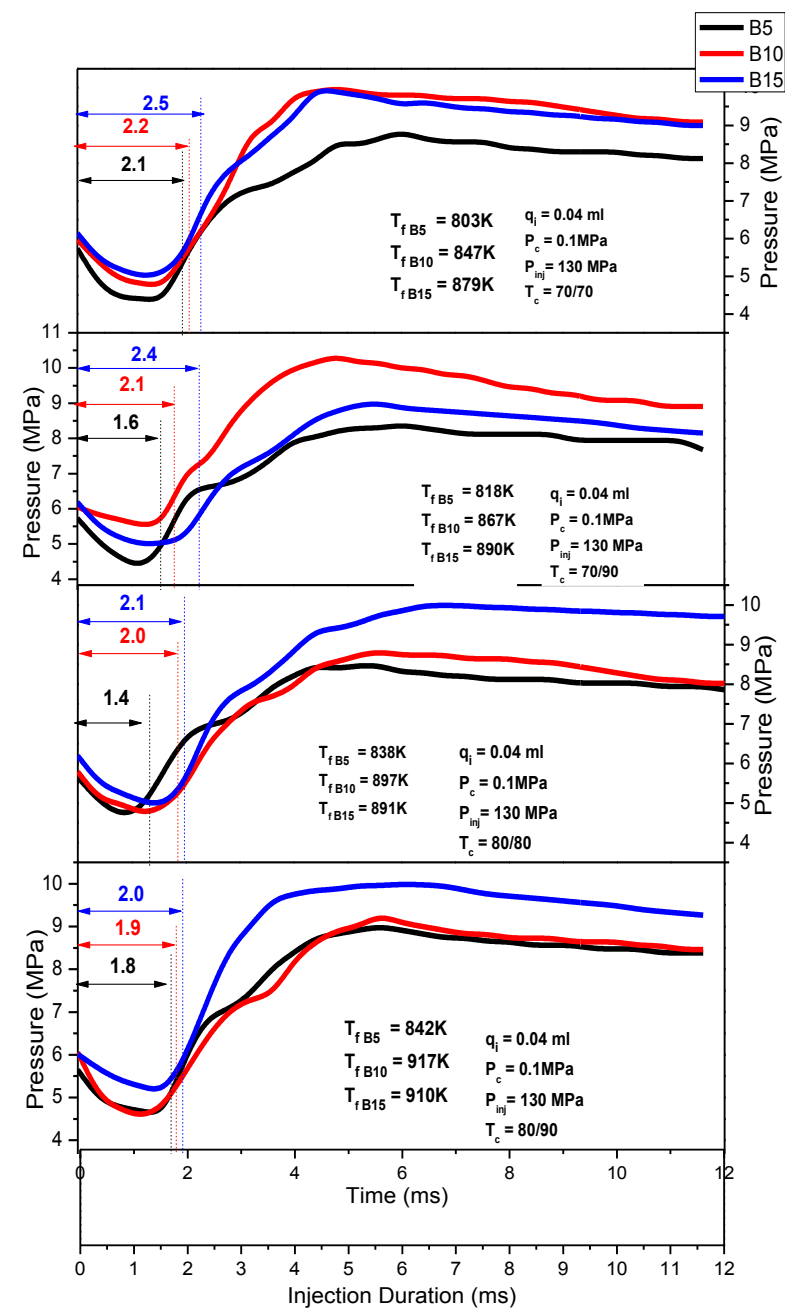

Fig. 3: Variation of Injection Duration of Palm-Oil Biodiesel at different Ambient Temperature

Figure 3 shows the graphs of combustion pressure against injection duration time under injection pressure $130 \mathrm{MPa}$ for B5, B10 and B15. Figure 3 illustrates about the influence of ambient temperature on injection duration with the ambient temperature in constant volume chamber (CVC) at $70^{\circ} \mathrm{C}$ and the ambient temperature in combustion chamber $(\mathrm{CC})$ at $70^{\circ} \mathrm{C}$ and $90^{\circ} \mathrm{C}$. Besides, the experiment also continued with the CVC ambient temperature at $80^{\circ} \mathrm{C}$ with $\mathrm{CC}$ ambient temperature at $80^{\circ} \mathrm{C}$ and $90^{\circ} \mathrm{C}$ respectively. As observed from Figure 3, the injection duration for B5, B10 and B15 are decreased with the increased of ambient temperature. The injection duration for B5 was decreased from $2.5 \mathrm{~ms}$ to $2.0 \mathrm{~ms}$ due to the increased in ambient temperature from the lowest CVC ambient temperature with $\mathrm{CC}$ ambient temperature 
at $70^{\circ} \mathrm{C}$ to the highest $\mathrm{CVC}$ ambient temperature of $80^{\circ} \mathrm{C}$ with $\mathrm{CC}$ ambient temperature of $90{ }^{\circ} \mathrm{C}$. The ignition delay time is reduced as the increased in ambient temperature reasoned by the reduction in bond dissociation energy. On the other hand, the fuel reactivity also been enhanced and the ignition delay become shorter. The methyl esters present in biodiesel split into smaller compounds when it entered into the combustion chamber which resulted higher spray angles and earlier ignition.

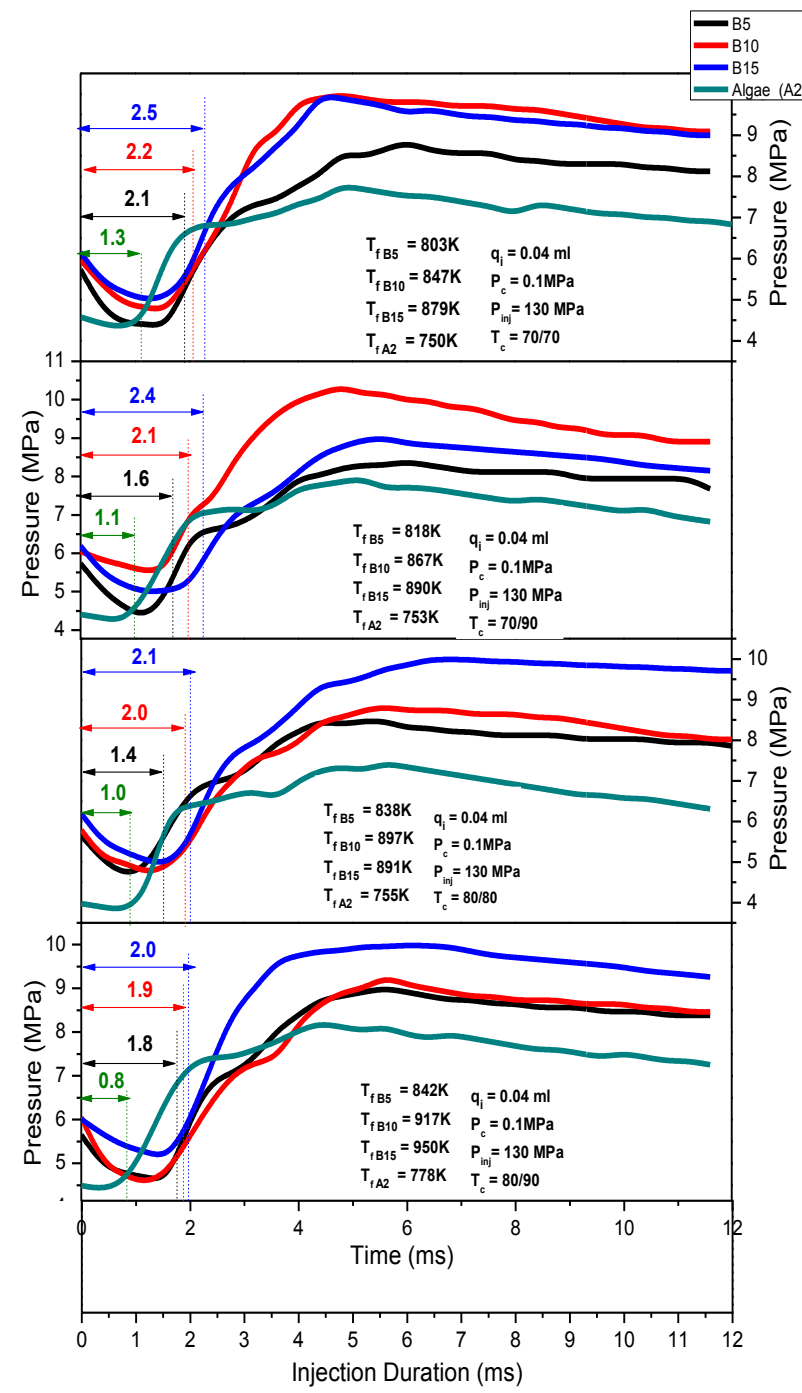

Fig. 4: Comparison of injection duration between A2 and Palm-Oil biodiesel under variant ambient temperature.

Figure 4 demonstrates the comparison between A2 and Palm-Oil biodiesel with injection duration at different ambient temperatures. Figure 4 clearly displayed that the injection duration for $\mathrm{A} 2$ is decreased as the ambient temperature increased. At CVC ambient temperature of $70^{\circ} \mathrm{C}$ and $\mathrm{CC}$ ambient temperature $70^{\circ} \mathrm{C}$, the injection duration for $\mathrm{A} 2$ is $1.3 \mathrm{~ms}$ and decreased gradually to 1.1 $\mathrm{ms}$ as the $\mathrm{CC}$ ambient temperature increased to $90^{\circ} \mathrm{C}$ while CVC ambient temperature remained the same. However, the trend continued to decrease to $0.8 \mathrm{~ms}$ at CVC ambient temperature of $80^{\circ} \mathrm{C}$ with $\mathrm{CC}$ ambient temperature of $90^{\circ} \mathrm{C}$. The biodiesel $\mathrm{A} 2$ has the lowest ignition delay compared to B5, B10 and B15 at high ambient temperature can be explained by the $\mathrm{C}-\mathrm{H}$ bond in A2 is weaken compared to $\mathrm{C}-\mathrm{H}$ bond in B5, B10 and $\mathrm{B} 15$. Thus, A2 have better fuel atomization and air-fuel mixing process which contributed by shorter ignition delay.

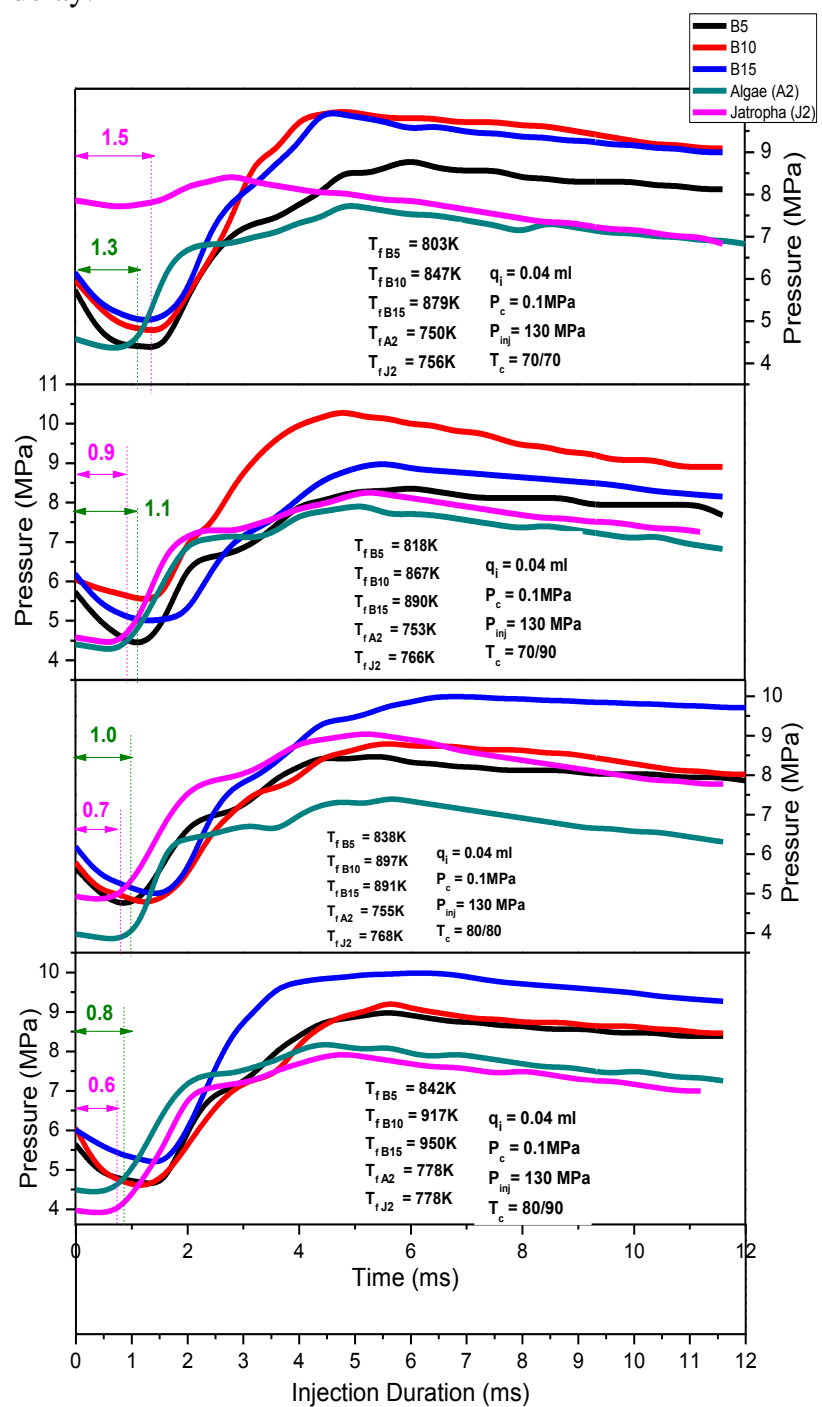

Fig. 5: Comparison of injection duration between $\mathrm{J} 2$ with A2 and Palm-Oil biodiesel under variant ambient temperature.

Figure 5 illustrates the comparison of injection duration between $\mathrm{J} 2$, A2 and Palm-Oil biodiesel under variant ambient temperatures. As observed from Figure 5, the injection duration for $\mathrm{J} 2$ is decreased as the ambient temperature increased. The injection duration for $\mathrm{J} 2$ is 1.5 $\mathrm{ms}$ at $\mathrm{CVC}$ ambient temperature of $70^{\circ} \mathrm{C}$ with $\mathrm{CC}$ ambient temperature $70^{\circ} \mathrm{C}$, and it decreased steadily to $0.9 \mathrm{~ms}$ as the $\mathrm{CC}$ ambient temperature risen to $90^{\circ} \mathrm{C}$ while CVC ambient temperature keep constant. Nevertheless, the injection duration is then continued to decrease to $0.6 \mathrm{~ms}$ when $\mathrm{CVC}$ ambient temperature is $80^{\circ} \mathrm{C}$ and $\mathrm{CC}$ ambient temperature at $90^{\circ} \mathrm{C}$. Consequently, J2 performed lower ignition delay compared to $\mathrm{A} 2$ with $0.6 \mathrm{~ms}$ and $0.8 \mathrm{~ms}$ at $\mathrm{CVC}$ ambient temperature of $80^{\circ} \mathrm{C}$ with $\mathrm{CC}$ ambient temperature $90^{\circ} \mathrm{C}$. 
The lower bond dissociation energy for $\mathrm{J} 2$ was attributed to this lower ignition delay.

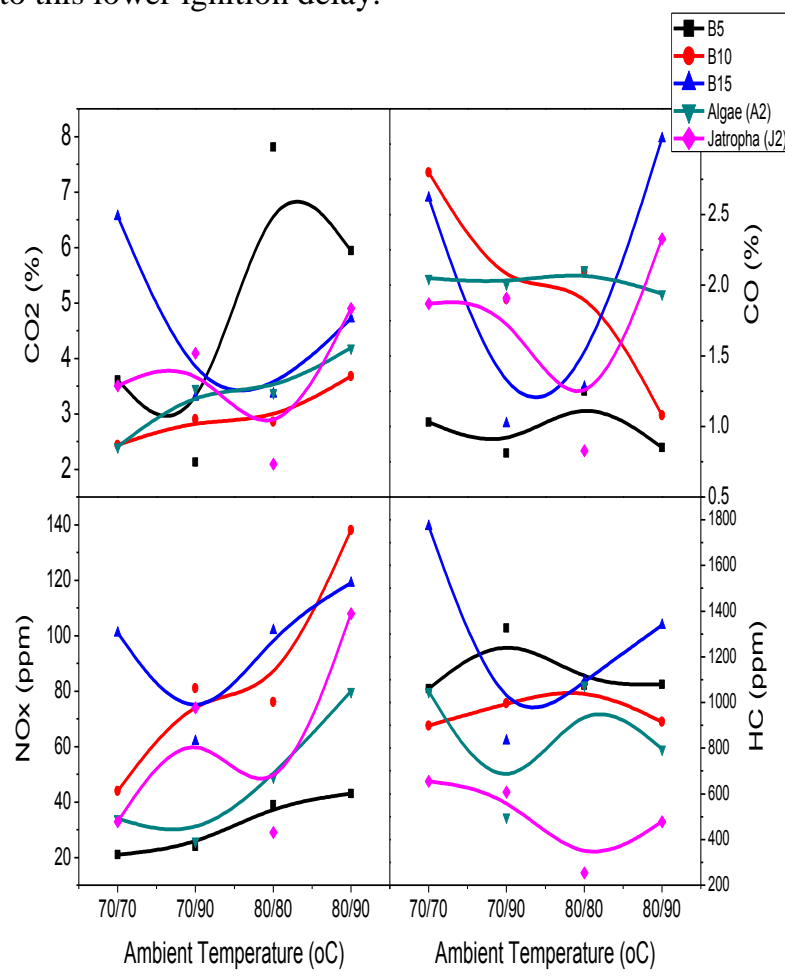

Fig. 6: Effect of ambient temperature on emission.

Figure 6 demonstrates the effect of ambient temperature towards to the exhaust emission levels of NOx and PM from diesel combustion when fueled with variant blending biodiesel derived palm oil, algae and Jatropha. The Figure 6 shows that the emission NOx and $\mathrm{CO} 2$ significantly increased while the $\mathrm{HC}$ and $\mathrm{CO}$ emission decreased when CVC ambient temperature at $80^{\circ} \mathrm{C}$ and $\mathrm{CC}$ ambient temperature at $90^{\circ} \mathrm{C}$. At $\mathrm{CVC}$ ambient temperature of $80^{\circ} \mathrm{C}$ with $\mathrm{CC}$ ambient temperature $90^{\circ} \mathrm{C}$, the formation of NOx is found achieved the highest for all type of fuels since NOx formation strongly depends on the combustion temperature. High combustion temperature increases the fuel atomization and penetration ratios as it also increases the homogeneity of charge that leads to NOx formation. Other than that, the emission of $\mathrm{HC}$ decreased with the increased of combustion temperature due to shorten ignition delay as combustion temperature increased. Moreover, better fuel mixed leaner which leads to the reduction in emission of $\mathrm{HC}$. Besides, the emission of $\mathrm{CO} 2$ also increased due to the complete combustion occurred at high combustion temperature which capable contributed to the lower emission of CO. Meanwhile, most of carbon in fuel are converted into $\mathrm{CO} 2$ rather than $\mathrm{CO}$ due to the complete combustion.

\section{Conclusion}

This study investigated the effects of ambient temperature on ignition delay, combustion process and emission with different types of biodiesel. Experiment was carried out with the Rapid Compression Machine (RCM) which applicable to the simulation of diesel combustion with combustion parameter can be varied. Ignition delay was analysed through Pico Scope 3000 Series PC Oscilloscopes and the components of emission from combustion process were investigated by gas analyzer. The temperature of cylinder and combustion chamber was varied between $70^{\circ} \mathrm{C}, 80^{\circ} \mathrm{C}$ and $90^{\circ} \mathrm{C}$. The results are summarized as follows:

1) Ignition delay decreased with increased of ambient temperature. The primary reason of shorter ignition delay for biodiesel at high combustion temperature is due to the fuel ignitibility and reactivity. Meanwhile, it also enhanced the fuel reactivity and shorter ignition delay.

2) High combustion temperature also contributed to the reduction of emission especially $\mathrm{HC}$ and $\mathrm{CO}$. Shorten ignition delay and better fuel mixing caused combustion achieved complete. In addition, the emission of NOx increased due to high combustion temperature and also influences to the greater of the fuel atomization and penetration ratios.

\section{Acknowledgements}

The authors also would like to thank the Ministry of Higher Education, Malaysia for supporting this research under Fundamental Research Grant Scheme (FRGS)(Vot 1466), FRGS (Vot 1054) and MTUN-COE Grant (Vot C009).

\section{References}

[1] U.S. Department of Energy (2003). Freedom Car \& Vehicle Technologies. Program. Office of Energy Efficiency and Renewable Energy. Retrieved on April 30, 2014 from http://energy.gov/eere/officeenergy-efficiency- renewable-energy.

[2] A. Khalid, N. Jaat, A. Sapit, A. Razali, B. Manshoor, I. Zaman and A.A. Abdullah, Performance And Emissions Characteristics Of Crude Jatropha Oil Biodiesel Blends In A Diesel Engine, International Journal of Automotive and Mechanical Engineering (IJAME), Vol. 11, (2015) pp. 2447-2457.

[3] Panayiotis Tsaousisa, Yaodong Wanga, Anthony P.Roskillya, Gary S. Caldwellb, Algae to energy: Engine performance using raw algal oil, Energy Procedia, vol. 61 (2014), pp. 656 - 659.

[4] Violeta Makareviciene, Sergejus Lebedevas, Paulius Rapalis, Milda Gumbyte,Virginija Skorupskaite, Justas Zaglinskis, Performance and emission characteristics of diesel fuel containing microalgae oil methyl esters, Fuel vol. 120, (2014), pp. 233239.

[5] Andsaler, A. R., Khalid, A., \& Jaat, N. (2017). Simulation and modeling of mixture formation under variant ambient condition and injection pressure of biodiesel spray. International Journal of Integrated Engineering, vol. 9, no. 3, pp. 18-23.

[6] Rais Hanizam Madon, Mas Fawzi, Shahrul Azmir Osman, Ahmad Jais Alimin, Mohd Azahari Razali, Muhamad Khairul Ilman Sarwani, Zulhelmy Zinil Abeden, Gas Chromatography Analysis of a C1-C5 
Hydrocarbon Column, International Journal of Integrated Engineering, Vol. 10 No. 1 (2018) p. 8591.

[7] Yanan Xu, Paul Hellier, Saul Purton, Frank Baganz, Nicos Ladommatos, Algal biomass and diesel emulsions: An alternative approach for utilizing the energy content of microalgal biomass in diesel engines, Applied Energy vol. 172 (2016), pp. 80-95.

[8] Soha S.M. Mostafa, Nour Sh. El-Gendy, Evaluation of fuel properties for microalgae Spirulina platensis bio-diesel and its blends with Egyptian petro-diesel, Arabian Journal of Chemistry vol. 10, (2017) pp. 2040-2050.

[9] Khalid, A., Effect of Ambient Temperature and Oxygen Concentration on Ignition and Combustion Process of Diesel Spray, Asian Journal of Scientific Research, Vol. 6, (2013), pp. 434-444.

[10] Liandong Zhu, Sustainable Biodiesel Production from Microalgae Cultivated with Piggery Wastewater, 2014. pg 27

[11] Edward G.Bellinger. Freshwater Algae: Identification and Use as Bioindicators. 2010 John Wiley \& Sons, Ltd. pg 1-3.

[12] Wilbur, A. A. Ignition Studies- The Determination of Auto Ignition Temperatures of Hydrocarbon Fuels. Washington DC: Naval Research Laboratory. 1974.

[13] M. P. B. Musculus, T. Lachaux, L. M. Pickett, and C. A Idicheria, Hydrocarbon Emissions in LowTemperature- Combustion Diesel Engines, vol. 2007, no. 724 (2007) pp. 776-790.

[14] Crua, C., Kennaird, D. A., Sazhin, S. S., and Heikal, M.R. Diesel Auto Ignition at Elevated In- Cylinder Pressures. UK: School of Engineering,University of Brighton. 2004.

[15] Khalid, A., Nursal, R. S., Tajuddin, A. S. A., \& Hadi, S. A. Performance and emissions characteristics of alternative biodiesel fuel on small diesel engine. ARPN Journal of Engineering and Applied Sciences, vol. 11(12), (2016), pp. 74247430.
[16] Khalid, A., \& Manshoor, B. (2012). Effect of high swirl velocity on mixture formation and combustion process of diesel spray doi:10.4028/www.scientific.net/AMM.229-231.695

[17] E. N. Balles and J. B. Heywood, Fuel-Air Mixing and Diesel Combustion in a Rapid Compression Machine, SAE Tech. Pap. 880206, 1988. 